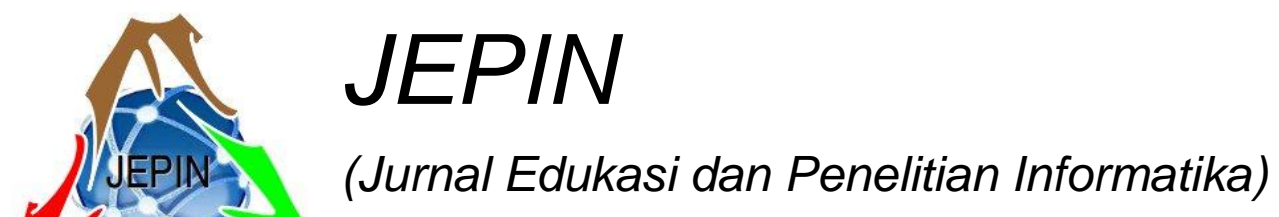

Vol. 4

No. 2

$\operatorname{ISSN}(e):$ 2548-9364 / ISSN(p) : 2460-0741

\title{
Perancangan Prototipe Aplikasi Mobile Tadzkirah
}

\author{
Agung Sasongko ${ }^{\# 1}$, Latifah $^{\# 2}$, Rabiatul Adwiya \\ ${ }^{\#}$ Program Studi Sistem Informasi, Universitas Bina Sarana Informatika PSDKU Pontianak \\ Jl. Abdurahman Saleh No.18a, Kota Pontianak \\ ${ }^{1}$ agung.ako@bsi.ac.id \\ ${ }^{2}$ latifah.lat@bsi.ac.id \\ ${ }^{3}$ rabiatul.rba@bsi.ac.id
}

\begin{abstract}
Abstrak - Pengguna internet kini semakin meningkat dari sisi kuantitas pengguna serta waktu. Rata-rata lama waktu yang digunakan para pengguna mengakses internet berkisar 4 jam sehari, hal ini sebagai acuan dasar penyebaran dakwah harus memanfaatkan internet sebagai medianya. Tadzkirah sebagai upaya pengingat kebaikan dalam ajaran agama Islam kepada para pemeluknya sudah dipandang perlu memanfaatkan aplikasi mobile berbasis internet sebagai asisten pribadi bagi untuk mengingatkan dalam hal kebaikan. Pada penelitian ini membahas mengenai perancangan prototipe aplikasi mobile Tadzkirah berbasis Android yang terintegrasi dengan website tadzkirah.org. Aplikasi mobile ini memiliki fitur menampilkan masjid terdekat serta kegiatan-kegiatan yang akan dilaksanakan di lokasi terdekat dengan menunjukkan lokasi kegiatan berupa peta Google Map. Perhitungan lokasi terdekat menggunakan euclidean distance, yaitu menghitung derajat kedekatan antara dua titik vektor. Nilai derajat yang digunakan kurang dari 0.6, atau radius sekitar 6-7KM dari titik lokasi pengguna. Aplikasi juga menyuguhkan nasehat-nasehat singkat kebaikan sehari-sehari. Bentuk data untuk komunikasi antara aplikasi mobile dengan web menggunakan format JSON. Dari hasil pengujian rata-rata waktu yang dibutuhkan menyuguhkan informasi 0.9 detik diluar pengambilan gambar, hal itu disebabkan format JSON lebih sederhana dari HTML pada website.
\end{abstract}

Kata kunci - Sistem informasi, Dakwah, Tadzkirah, Website.

\section{Pendahuluan}

Hasil riset yang dikeluarkan oleh Hootsuitetm, data per Juli 2018 mengungkapkan bahwa penggunaan internet menunjukkan bahwa prosentase pengguna internet di dunia mencapai 54\%, serta trafik penggunaan pada perangkat telepon genggam sebesar $52.6 \%$ [1]. Sedangkan di Indonesia sendiri menurut data yang dilansir per Maret 2018 oleh APJII menunjukkan penetrasi pengguna internet di Indonesia sebesar 54.7\% [2]. Sedangkan data berkaitan lama pengguna internet oleh masyarakat Indonesia adalah 1-3 jam sebanyak 43.89\%, 4-7 jam sebanyak $29.63 \%$ dan lebih dari 7 jam sebanyak $26.48 \%$ [3]. Kegiatan dakwah akan sangat efektif pada jaman ini dengan menggunakan internet sebagia medianya
Tadzkirah adalah upaya mengingatkan dalam hal kebaikan dalam agama Islam [4]. Tadzkirah dapat berupa nasehat-nasehat pendek yang mengingatkan orang kepada Allah, melakukan kebaikan dan mencegah prilaku tidak terpuji. Upaya menyampaikan nasehat pada jaman kini perlu melakukan transformasi agar lebih tepat sasaran. Memanfaatkan internet dan aplikasi mobile sebagai salah satu cara untuk meningkatkan keberhasilan dalam hal dakwah.

Beberapa cara untuk menyebarluaskan dakwa secara cepat yaitu dengan menggunakan media Internet berupa aplikasi website maupun aplikasi mobile. Untuk lebih meningkatkan interaktif kepada pengguna maka aplikasi mobile dapat menjadi alternatif, dikarenakan aplikasi mobile memiliki kemampuan untuk menampilkan pemberitahuan berupa notif pada smartphone.

Pada penelitian terdahulu oleh Agung Sasongko, Latifah dan Rabiatul Adwiyah pada prosiding Seminar Nasional Inovasi dan Tren (SNIT) 2018 telah dibahas tentang Sistem Informasi Manajemen Kegiatan Tazkirah berupa aplikasi berbasis website, aplikasi website saat ini perlu juga ditunjang aplikasi mobile untuk meningkatkan interaksi kepada pengguna [4].

Penelitian oleh Alhidayatillah pada penelitiannya yang berjudul Dakwah Dinamis di Era Modern (Pendekatan Manajemen Dakwah membahas mengenai peran upaya dakwah yang dilakukan secara dinamis agar kegiatan manusia di dunia berlandaskan agama serta menyeseuaikan dengan kondisi masyarakat yang sedang terjadi [5].

Aplikasi mobile tazkirah dikembangkan untuk membantu dalam hal manajemen pengetahuan materi dakwah dan waktu pelaksanaannya yang dapat terdistirbusi luas kepada masyarakat. Penelitian terkait mengenai manajemen pengetahuan kegiatan oleh Wahyudi dan Sasongko yang telah melakukan penelitian pada bidang tersebut bahwa metode specific action dapat dimanfaatkan untuk mengetahui tata laksana kegiatan untuk mengetahui masalah dan solusi yang digunakan pada tiap pelaksanaan kegiatan [6].

Tujuan penulisan ini untuk mengungkapkan rancangan aplikasi mobile tadzkirah berbasis Android untuk masyarakat muslim agar mengetahui lokasi masjid 
disekitarnya, serta kegiatan apa saja yang akan berlangsung di daerah sekitarnya.

\section{TINJAUAN PUSTAKA}

\section{A. Mobile Application}

Aplikasi mobile atau bahasa Inggrisnya Mobile Application adalah perangkat lunak yang berjalan di perangkat mobile yang digunakan untuk layanan bergerak[7]. Perbedaan mendasar antara aplikasi dengan aplikasi mobile adalah aplikasi mobile dikembangkan di dalam framework, sedangkan aplikasi pada umumnya berjalan secara langsung di Sistem Operasi.

\section{B. Android}

Android merupakan sistem operasi berupa lapisanlapisan yang terdiri dari sistem operasi berbasis Linux, Android Runtime dan Application Framework [8]. Arsitektur android berupa 4 lapisan [9] seperti terlihat pada Gambar 1, yaitu: Lapisan 1 adalah kernel Linux sebagai lapisan yang paling dekat dengan mesin, lapisan ini mengatur perangkat keras. Lapisan 2 merupakan Libraries dan Android Runtime, lapisan ini terdiri dari pustaka-pustaka untuk mengelola perangkat keras serta Android Runtime sebagai inti dari Sistem Operasi Android yang menggunakan Virtual Dalvik Machine. Lapisan 3 adalah Application Framework, merupakan kerangka kerja aplikasi-aplikasi yang akan berjalan diatasnya, dan Lapisan 4 adalah segala aplikasi yang berjalan di Android.

\begin{tabular}{|c|c|c|c|c|}
\hline \multicolumn{5}{|c|}{ APPLICATIONS } \\
\hline Home & Contacts & Phone & Browser & $\ldots$ \\
\hline \multicolumn{5}{|c|}{ APPLICATION FRAMEWORK } \\
\hline Activity Manager & \multicolumn{2}{|c|}{ Widnwos Manager } & Contenct Providers & View System \\
\hline $\begin{array}{l}\text { Package } \\
\text { Manager }\end{array}$ & $\begin{array}{c}\text { Telephony } \\
\text { Manager }\end{array}$ & $\begin{array}{l}\text { Resource } \\
\text { Manager }\end{array}$ & $\begin{array}{l}\text { Location } \\
\text { Manager }\end{array}$ & $\begin{array}{c}\text { Notification } \\
\text { Manager }\end{array}$ \\
\hline \multicolumn{4}{|c|}{ LIBRARIES } & RUNTIME \\
\hline Surface Manager & Media Framework & \multicolumn{2}{|c|}{ SQLite } & Core Libraries \\
\hline OpenGL/ES & FreeType & \multicolumn{2}{|c|}{ WebKit } & Dalvik Virtual Machine \\
\hline SGL & SSL & \multicolumn{2}{|c|}{ Libc } & Android Runtime (ART) \\
\hline \multicolumn{5}{|c|}{ LINUX KERNEL } \\
\hline Display Driver & Camera Driver & \multicolumn{2}{|c|}{ Flash Memory Driver } & Binder (IPC) Driver \\
\hline Keypad Driver & WiFi Driver & \multicolumn{2}{|c|}{ Audio Drivers } & Power Management \\
\hline
\end{tabular}

\section{Tazkirah}

Tazkirah adalah suatu bentuk untuk mengingakt kembali atau memberi peringatan kepada pemeluk Islam untuk tidak melakukan perbuatan keji [4]. Kegiatan tazkirah tidak lepas dari upaya dakwah umum yang diwajibkan kepada setiap muslim untuk saling mengingatkan kebaikan agar mencegah perbuatan keji dan menjalnakn perbuatan kebaikan. Penyampaian dakwah sat ini dapat memanfaatkan media teknologi informasi, agar pesan mengenai kebutuhan hidup duniawi dapat lebih luas dan lebih cepat tersebar [5].

\section{Push Notification}

Push notification merupakan suatu konsep mekanisme kerja mengirimkan suatu event/kejadian oleh server pengendali ke aplikasi client [11]. Pada implementasinya, pengiriman event memerlukan keterhubungan jaringan data yang memiliki masalah dalam kemampuan menjangkau client, yaitu: alamat perangkat client yang tidak bersih dan kemampuan akses ke perangkat client. Penerapan push notification sederhananya adalah aplikasi client melakukan pembacaan informasi terbaru ke server secara periodik, namun hal ini sangat berpengaruh terhadap konsumsi daya dan bandwidth. Pada saat ini kemampuan push notification pada Android dapat memanfaatkan library yang telah disediakan oleh google yaitu Firebase Cloud Messaging, efisiensi bandwidth dan daya dapat dicapai. Tujuan push notification adalah mendapati informasi baru di server untuk tahu kapan untuk memulai sinkronisasi data.

\section{E. Euclidean Distance}

Perhitungan jarak kemiripan titik ada banyak diantaranya Canberra distance, manhattan distance, city block distance, minkowski distance, bray curtis distance dan lain sebagainya. Namun pada penelitian ini tidak menitik beratkan pada keakuratan jarak, dan hanya memberikan saran lokasi terdekat dengan pengguna maka euclidean distance yang dipilih dikarenakan rumus perhitungan yang sederhana. Menurut Sutoyo dalam Wurdianarto menjelaskan bahwa Euclidean Distance adalah metode mengukur jarak kesamaan dua vektor [12] . Rumus dari euclidean distance adalah:

$$
d_{i j}=\sqrt{\sum_{k=1}^{n}\left(x_{i k}-x_{j k}\right)^{2}}
$$

Keterangan:

$D_{i j} \quad=$ derajat perbedaan

$\mathrm{n} \quad=$ jumlah vektor

$\mathrm{x}_{\mathrm{ik}} \quad=$ vektor masukan

$\mathrm{x}_{\mathrm{ij}} \quad=$ vektor pembanding

Rumus euclidean distance ini digunakan untuk mengetahui lokasi masjid maupun lokasi kegiatan yang dekat dengan pengguna berdasarkan derajat perbedaan lokasi dengan pengguna.

\section{PERANCANGAN SISTEM}

Pelaksanaan penelitian ini proses pengembangan perangkat lunaknya menggunakan pendekatan purwarupa (prototype) yang dilakukan secara berulang kepada calon pengguna [13]. Hal ini bertujuan untuk mendapatkan gambaran aplikasi mobile tadzkirah yang cocok untuk diterapkan dimasyarakat. Langkah-langkah prototipe dapat dilihat pada Gambar 2. 


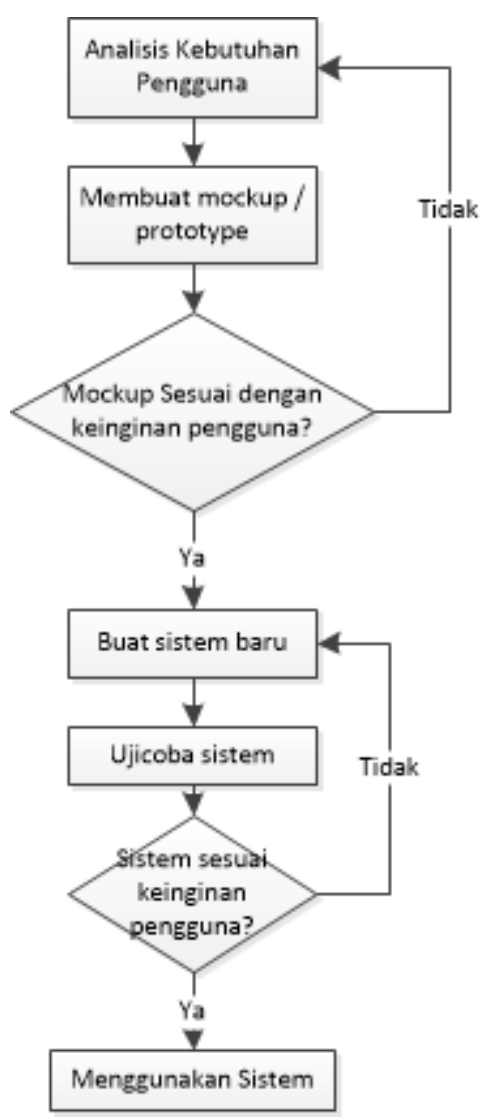

Gambar 2. Langkah-langkah prototipe

\section{A. Kebutuhan Fungsional}

1) Memiliki tampilan banner untuk menampilkan kegiatan apa yang harus diketahui oleh masyarakat.

2) Menampilkan nasehat pendek kebaikan sehari-hari kepada masyarakat sebagai pengguna aplikasi.

3) Menampilkan lokasi masjid terdekat dan menampilkan informasi alamatnya serta kegiatan apa saja yang akan dilaksanakan di masjid.

4) Menampilkan daftar kegiatan yang akan berlangsung di daerah sekitar pengguna serta peta yang disuguhkan berupa google map.

\section{B. Kebutuhan non-Fungsional}

1) Aplikasi Mobile Tadzkirah dapat diakses oleh seluruh masyarakat, maka penerapan sistem tersebut harus dalam jaringan (daring) Internet.

2) Aplikasi harus dapat berjalan diperangkat mobile berbasis Android.

3) Komunikasi data harus efisien dan tidak mahal.

4) Menyediakan konten berupa teks dan gambar.

\section{Use Case Diagram}



Gambar 3. Use case diagram

\section{Bagan Penerapan Sistem Informasi}

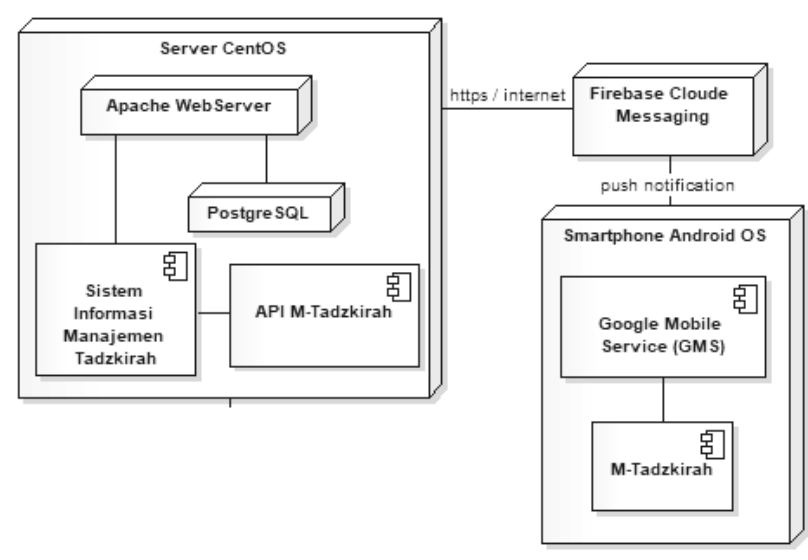

Gambar 4. Deployment diagram

Penjelasan konfigurasi penerapan sistem ditujukan pada gambar 4. Penerapan aplikasi nantinya menggunakan peladen berbasis linux yang telah terpasang apache-server dan aplikasi database MySQL. Aplikasi dipasang di sisi peladen adalah Sistem Informasi Manajemen Tadzkirah dan API M-Tadzkirah. Seperti yang diketahui pada saat ini RESTful dalam bentuk format JSON adalah cara yang paling efisien dalam mengirimkan format komunikasi data ketimbang format XML. Mengingat kebutuhan nonfungsional yang mengharapkan komunikasi data yang low-cost maka format JSON menjadi pilihan.

Tiap kali adanya informasi kegiatan yang dipublikasikan oleh pengguna e-tazkirah, maka masyarakat pengguna M-Tazkirah mendapatkan pesan pemberitahuan melalui Firebase Cloud Messaging (FCM) 
yang merupakan layanan komunikasi push notification dari google agar dapat diterima oleh perangkat Android secara cepat selama terhubung ke layanan internet. Pada aplikasi websitenya harus mengimplementasikan pemicu untuk memberikan pesan ke server firebase untuk dilakukan push notification ke aplikasi M-Tazkirah. Implementasi berupa kode pengiriman post json data ke peladen firebase pada tiap penyimpanan data kegiatan dan nasehat pada dashboard sistem e-Tazkirah.

\section{E. Bagan Komponen}

Pengembangan aplikasi berorientasi obyek dapat memanfaatkan library obyek yang telah pernah ada dibuat sebelumnya. Pada pengembangan aplikasi mobile tadzkirah berbasis Android menggunakan beberapa library diantaranya dapat dilihat pada Gambar 5.

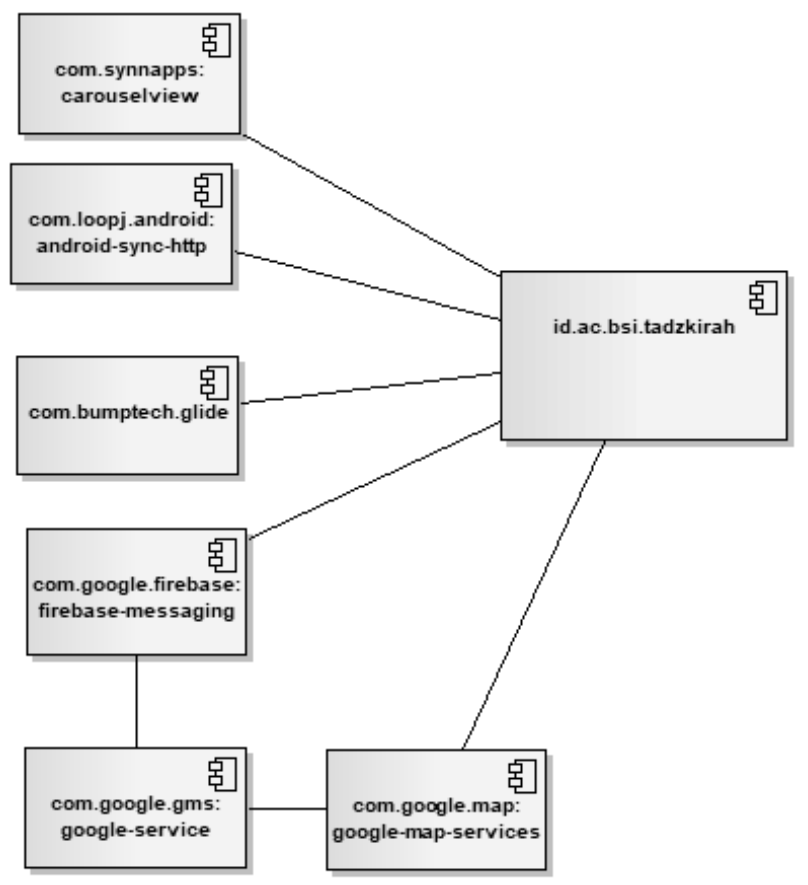

Gambar 5. Bagan komponen

\section{HASIL IMPLEMENTASI DAN PENGUJIAN}

Implementasi Mobile Tazkirah tidak lepas dari implementasi aplikasi Tazkirah berbasis web (e-tazkirah), karena e-tazkirah sebagai tulang punggung transaksi data yang sebenarnya terjadi. Pada sisi server ditambahkan modul API (Application Programming Interface) untuk mengkomunikasikan data yang ada di server dengan aplikasi mobile.

\section{A. Banner Kegiatan}

Banner kegiatan bertujuan sebagai publikasi / promosi terhadap segala kegiatan yang ditawarkan oleh para mubaligh, pengurus masjid maupun organisasi pendakwah.

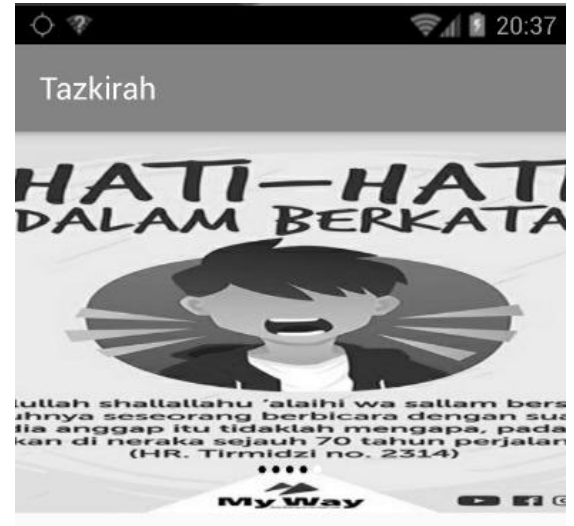

Gambar 6. Banner promosi kegiatan

Untuk menampilkan banner carousel seperti gambar 6 menggunakan komponen viewpager yang dilakukan modifikasi agar berganti slide pada waktu yang telah ditentukan secara rotasi.

\section{B. Peta Lokasi Masjid Terdekat}

Menampilkan peta google map yang berisikan masjid terdekat dengan pengguna aplikasi. Untuk mendapatkan data masjid terdekat maka perlu ada data masjid yang telah disimpan sebelumnya beserta koordinatnya.



Gambar 7. Lokasi Masjid terdekat

Untuk menentukan lokasi terdekat dengan pengguna, caranya dengan menghitun antara koordinat pengguna dengan koordinat-koordinat masjid yang ada di data masjid di server menggunakan perhitungan euclidean distance. Setelah didapat derajat kedekatannya maka ambil kedekatan pada rentang nilai derajat kurang dari 0.6 yang kurang lebih pada jangkaun 6-7 KM. 


\section{Informasi Masjid}

Memberikan informasi masjid dengan pengguna secara detail. Library yang digunakan untuk mencari rute antara pengguna dengan lokasi masjid adalah com.github.jdalexander:library:1.1.0. Namun dikarenakan adanya kebijakan dari google sebagai penyedia layanan perhitungan rute jarak, maka layanan ini tidak akan efektif bila pengembang aplikasi tidak melakukan biaya berlangganan kepada goolge map untuk fitur route destination.

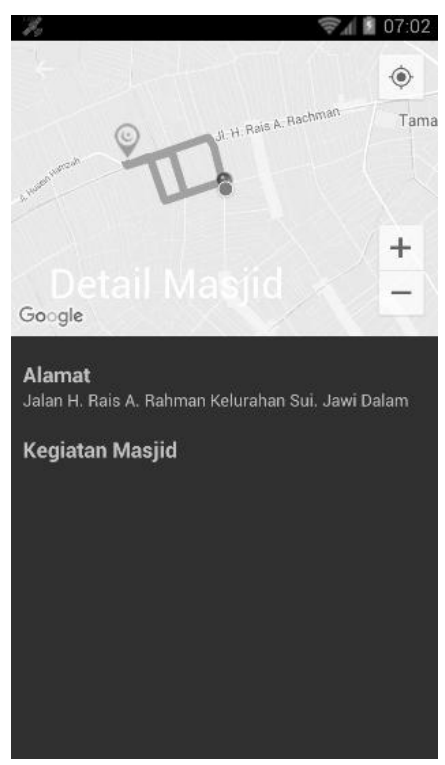

Gambar 8. Detail Informasi Masjid

Pada Gambar 8 menampilkan alamat lengkap serta kegiatan-kegiatan masjid yang akan berlangsung.

\section{Nasehat Kebaikan}

Nasehat kebaikan merupakan konten bergambar yang berisi tulisan ringan sebagai pengingat hal kebaikan. Menu ini dapat dilihat pada Gambar 9.

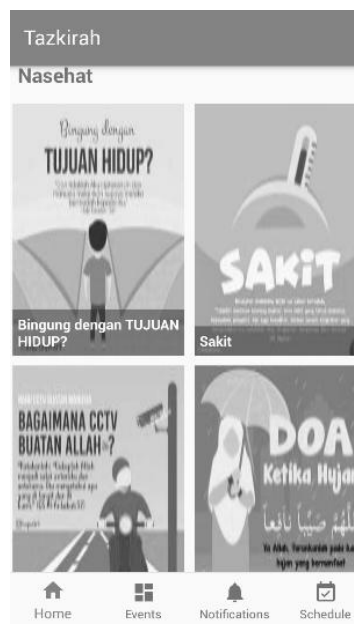

Gambar 9. Nasehat kebaikan.

\section{E. Kegiatan}

Kegiatan menampilkan informasi berupa waktu kegiatan, tempat kegiatan, penyelenggara serta deskripsi kegiatan. Menampilkan juga mubaligh yang mengisi ceramah seperti terlihat pada Gambar 10.



Pada Gambar 11 menampilkan juga lokasi kegiatan dilaksanakan dengan memanfaatkan library dari Google Map.



Gambar 11. Lokasi Kegiatan 


\section{F. Notifikasi Kegiatan}

Setiap adanya kegiatan baru yang dimasukkan pada database oleh pengelola e-tazkirah, maka sistem akan memberikan notifikasi ke aplikasi mobile.

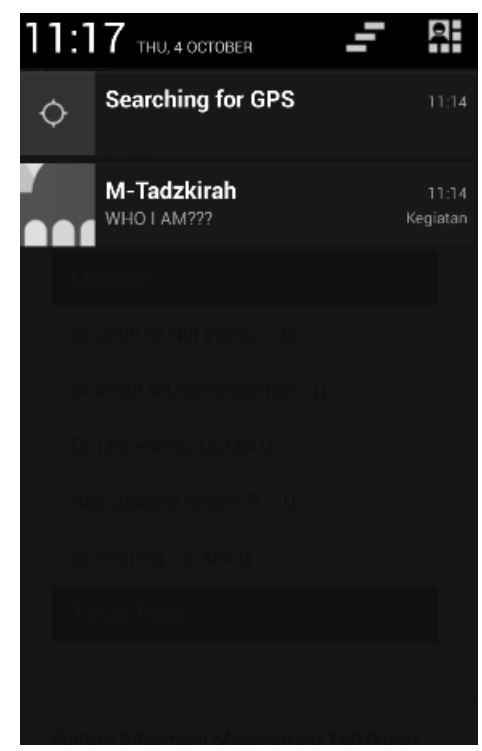

Gambar 12. Notifikasi Event Baru.

Dengan dibuatkan fitur-fitur tersebut diharapkan masyarakat sebagai pengguna aplikasi M-Tadzkirah dapat mengetahui informasi terkini seputar kegiatan dakwah yang terdai di sekitarnya seperti terlihat pada Gambar 12.

\section{G. Pengujian Kecepatan dan Ukuran Memuat data}

Pada tahapan pengujian ini yaitu menguji load data aplikasi yang menggunakan format JSON dan gambar kemudian direpresentasikan ke tampilan pada aplikasi MTadzkirah. Pengukuran menggunakan mode debug pada Android Studio dengan melakukan perhitungan pencatatan waktu mulai proses dan waktu akhir proses. Lama proses adalah proses akhir dikurang proses awal. Uji coba dilakukan pada perangkat Smartphone Android Xiaomi Note 4X. berikut hasilnya:

TABEL 1.

Pengujian KeCEPATAN LOAD DATA.

\begin{tabular}{|l|l|r|}
\hline No. & \multicolumn{1}{|c|}{ Bagian } & $\begin{array}{c}\text { Waktu } \\
\text { (milisecond) }\end{array}$ \\
\hline 1 & Carousel Banner & 18.622 \\
\hline 2 & Masjid Terdekat & 836 \\
\hline 3 & Nasehat & 908 \\
\hline 4 & Kegiatan & 1.134 \\
\hline 5 & Notifikasi & 2.916 \\
\hline & $\begin{array}{l}\text { Rata-rata load json } \\
(2,3,4)\end{array}$ \\
\hline
\end{tabular}

Dari hasil pengujian yang ditunjukan pada Tabel 1 menunjukkan bahwa load data yang berjenis JSON membutuhkan waktu rata-rata 0.9 detik, sedangkan yang bergambar seperti Carousel Banner membutuhkan waktu 18 detik. Hal tersebut dipengaruhi oleh ukuran gambar yang diunduh dan kecepatan internet. Notifikasi dihitung mulai dari proses penyimpanan terjadi kemudian mengirimkan data ke server firebase hingga diterima oleh client, waktu menunjukkan 2.916 second, atau hampir 3 detik. Teknologi firebase dari google menunjukkan efisiensi bandwidth dan sumberdaya battery perangkat karena tidak harus melakukan pengecekan secara berkala untuk mengetahui adanya data baru yang masuk.

\section{KESIMPULAN}

Aplikasi mobile yang dibangun adalah sebatas prototipe yang perlu dilakukan penyesuaian untuk penggunaan yang lebih luas. Hasil pengujian yang telah dilakukan hanya pada lingkup kawasan kota Pontianak. Implementasi aplikasi dapat juga digunakan pada wilayah yang lebih luas, dengan melengkapi data masjid, mubaligh dan kegiatan dakwah beserta dengan posisi koordinatnya.

Aplikasi mobile tadzkirah dapat mengambil data dari server berupa format JSON yang kemudian direpresentasikan pada aplikasi M-Tadzkirah pada waktu yang efisien rerata 0.9 detik. Mendapatkan data lokasi masjid terdekat dapat menggunakan rumus euclidean dengan membandingkan lokasi perangkat pengguna dengan lokasi masjid yang ada di database. Notifikasi yang dikirimkan melalui web tadzkirah dikirim ke server firebase hingga diterima ke pengguna memakan waktu rata-rata 2-4 detik.

Saran Pengembangan aplikasi kedepannya harus dilakukan sinkronisasi ke data provider calendar di Android untuk segala agenda dakwah yang ada di sekitar wilayah pengguna. Pembuatan menu pengaturan untuk mengaktifkan maupun mematikan notifikasi serta reminder kegiatan dakwah yang akan berlangsung.

\section{UCAPAN TERIMA KASIH}

Saya dan tim Penelitian Dosen Pemula dari kampus Universitas Bina Sarana Informatika mengucapkan banyak terima kasih kepada KEMENRISTEKDIKTI pada program hibah Penelitian Dosen Pemula tahun Anggaran 2018 sebagai pihak yang memberikan pendanaan penelitian.

Ucapan terima kasih juga kepada semua pihak yang telah mendukung baik pengurus masjid, organisasi masyarakat dakwah maupun para mubaligh di lingkungan kota Pontianak telah bersedia memberikan data selama proses penelitian dilaksanakan.

\section{REFERENSI}

[1] M. Mehmood, "Essential Insights Into Internet, Social Media Mobile And Ecommerce Use Around The World," 2018. [Online]. Available: https://www.digitalinformationworld.com/2018/07/globalinternet-stats-infographic.html. [Accessed: 25-Sep-2018]. 
[2] APJII, "Buletin APJII Edisi 22 Maret 2018," Buletin APJII, Jakarta, p. 7, Mar-2018.

[3] S. Rakhma, "Berapa Lama Rata-rata Orang Indonesia Gunakan Internet dalam Sehari? Artikel ini telah tayang di Kompas.com dengan judul 'Berapa Lama Rata-rata Orang Indonesia Gunakan Internet dalam Sehari?', https://ekonomi.kompas.com/read/2018/02/19/184500826/bera pa-la," kompas.com, 2018. [Online]. Available: https://ekonomi.kompas.com/read/2018/02/19/184500826/bera pa-lama-rata-rata-orang-indonesia-gunakan-internet-dalamsehari. [Accessed: 25-Sep-2018].

[4] A. Sasongko, Latifah, and R. Adwiyah, "Sistem Informasi Manajemen Kegiatan Tazkirah Terpadu: Konsep dan Rancangan," in Seminar Nasional Inovasi dan Tren (SNIT) 2018, 2018, p. 7.

[5] N. Alhidayatillah, "Dakwah Dinamis Di Era Modern (Pendekatan Manajemen Dakwah)," J. An- nida J. Pemikir. Islam, vol. 41, no. 2, pp. 252-276, 2017.

[6] M. Wahyudi and A. Sasongko, "Knowledge Managemen System pada Event Organizer Kampus Bina Sarana Informatika (BSI) Menggunakan Pendekatan Metode Specific Action Berbasis Web Mobile," in SENARAI 2014, 2014, pp. 9 13.

[7] F. Sari, Metode Dalam Pengambilan Keputusan. Yogyakarta: Budi Utama, 2018.

[8] A. Sasongko, "Integrasi Data Website students.bsi.ac.id Untuk
Mobile Infokampus Berbasis Android Menggunakan Ekstraksi HTML," J. Ilmu Pengetah. dan Teknol. Komput., vol. 2, no. 2, pp. 146-155, 2017.

[9] J. Kham and S. Shahzad, "Android Architecture and Related Security Risks," www.researchgate.net, 2018. [Online]. Available: https://www.researchgate.net/figure/Architectureof-Android-Operating-

System fig2 299430490? sg=uW28LHcHeUwxg8YpOugnj5 u7JMWvlrusToCbtzDAGFO7Ufb1RG6npKtqKMKHyYtPXEj L0znSfeABJNbmWX00LittiquKNFm4wx8SWpkLqA.

[Accessed: 25-Sep-2018].

[10] M. Qiu, W. Dai, and K. Gai, Mobile Applications Development with Android: Technologies and Algorithms. Boca Raton: CRC Press, 2016

[11] I. Warren, A. Meads, and C. Paniagua, "Push Notification Mechanisms for Pervasive Smartphone Applications," IEEE Pervasive Computing ( Volume: 13 , Issue: 2 , Apr.-June. 2014 ), pp. 61-71, 2014.

[12] S. R. Wurdianarto, S. Novianto, and U. Rosyidah, "PERBANDINGAN EUCLIDEAN DISTANCE DENGAN CANBERRA DISTANCE PADA FACE RECOGNITION,' Techno.COM, vol. 13, no. 1, pp. 31-37, 2014.

[13] S. Mulyani, Metode Analisis dan Perancangan sistem, 2nd ed. Bandung: Abdi Sistematika, 2016. 